\title{
Sargassum epifaunal communities vary with canopy size, predator biomass and seascape setting within a fringing coral reef ecosystem
}

\author{
Yi-Yang Chen*, Paul Cooper, Christopher J. Fulton
}

Ecology and Evolution, Research School of Biology, The Australian National University, Canberra ACT 2601, Australia

\begin{abstract}
Tropical seascapes are comprised of a range of patch habitat types, yet we have only a partial understanding of how local patch condition and seascape position may influence patterns of marine biodiversity, particularly for invertebrate taxa. We investigated how the epifaunal abundance and biomass of tropical Sargassum varied with canopy size (volume, total length and dry weight), local patch conditions (macroalgal composition, canopy structure and invertivorous fish biomass) and seascape setting (nearshore, lagoon and back reef) within the Ningaloo fringing reef ecosystem, Australia. A total of 49431 epifauna, dominated by crustaceans and molluscs, were extracted from the thalli of 81 tropical Sargassum polycystum individuals. Epifaunal abundance and biomass were most strongly correlated with host Sargassum canopy volume and dry weight, respectively. Epifaunal abundance and biomass also varied significantly among separate Sargassum meadow patches, with a significant interaction between canopy size and seascape position. Considerable site-level variations in epifaunal biomass density (mg per g Sargassum dry weight) were best predicted by either seascape context or local invertivorous fish biomass. Sargassum within meadows furthest from the back reef tended to have the highest epifaunal biomass (dominated by molluscs), while meadows closest to the back reef were dominated by crustacea. Sargassum within meadows with a high local abundance of invertivorous labrids and serranids tended to have the lowest epifaunal biomass. Strong Sargassum canopy size-epifauna relationships indicate that even small differences in canopy extent have major flow-on effects for the trophic function of tropical marine ecosystems by affecting the epifaunal secondary productivity available to higher-order consumers, such as fishes.
\end{abstract}

KEY WORDS: Tropical macroalgae $\cdot$ Epifauna $\cdot$ Invertivorous fish $\cdot$ Crustacea $\cdot$ Mollusca $\cdot$ Biomass $\cdot$ Patch habitat

Resale or republication not permitted without written consent of the publisher

\section{INTRODUCTION}

Tropical seascapes can be composed of a range of habitat-forming organisms that create patches of coral, seagrass, mangroves, and macroalgae embedded within a matrix of carbonate reef and sand. Emerging evidence indicates that local conditions can interact with the seascape position of these biogenic patch habitats to shape spatial patterns of tropical marine biodiversity and ecosystem function (Berkström et al. 2013, Hensgen et al. 2014, van Lier et al. 2018). For in- stance, the local abundance of macroalgal-associated fishes has been linked to within-patch habitat complexity and proximity to nearby patches of coral, seagrass and/or macroalgal habitat (Berkström et al. 2013, van Lier et al. 2018). The extent to which these within-patch and seascape effects operate at lower trophic levels (e.g. small-bodied invertebrates), however, remains poorly understood.

Epifauna are invertebrates (typically $0.5-10 \mathrm{~mm}$ long) that occupy the living canopy of other organisms, such as macroalgae and corals (Edgar 1990a, Edgar \& 
Aoki 1993, Kramer et al. 2017). Often extremely abundant with rapid rates of turnover (growth and mortality), the productivity of these epifauna can support large populations of higher-order consumers, such as fishes, and underpin major pathways of energy and nutrient transfer in marine ecosystems (Edgar \& Aoki 1993, Taylor 1998, Kramer et al. 2017). In marine ecosystems, epifaunal communities have been documented within abiotic substrata (rubble and sand) as well as within the canopy of corals, seagrasses and macroalgae (Stella et al. 2010, Kramer et al. 2014, Tano et al. 2016). Current evidence suggests that epifaunal abundance and diversity may be highest within macroalgal microhabitats, including both erect canopy-forming taxa as well as turf communities of the epilithic algal matrix (Kramer et al. 2017), which are targeted by a range of invertivorous reef fishes (Kramer et al. 2015, Wenger et al. 2018).

Canopy-forming macroalgae of the genus Sargassum are widespread along coastlines of the world, where they can form extensive meadow habitats. Sargassum meadows are increasingly being recognised as an integral component of tropical marine ecosystems, where they support primary production and provide habitat for a diversity of juvenile and adult fishes (Fulton et al. 2019). Canopy structure and composition of tropical Sargassum meadows and their associated reef fish communities can vary strongly over space and time due to local environmental conditions and seascape context (Ateweberhan et al. 2009, Fulton et al. 2014, van Lier et al. 2018). Moreover, limited evidence suggests tropical Sargassum canopies can contain a range of epifaunal invertebrates, which may vary in abundance according to macroalgal canopy size (Leite \& Turra 2003, Wenger et al. 2018) and the presence of invertivorous fishes (Edgar \& Aoki 1993). However, we lack an understanding of the relative importance of these local factors alongside seascape context for shaping the relative abundance of Sargassum epifauna, which are likely to be a key trophic resource for many higher-order consumers found within tropical macroalgal meadows (Berkström et al. 2013).

To better understand the likely drivers of tropical macroalgal epifaunal community structure, we used an extensive network of Sargassum-dominated meadows within a fringing coral reef ecosystem to determine (1) to what extent epifaunal abundance (in terms of number of individuals) and biomass are correlated with different measures of host Sargassum canopy size (total length, volume and dry weight), (2) whether epifaunal community structure varies with seascape position (nearshore, lagoon and back reef) and (3) if local conditions of within-patch macroalgal composition and invertivorous fish biomass can predict spatial variations in Sargassum epifaunal community structure.

\section{MATERIALS AND METHODS}

\subsection{Study location}

Ningaloo Reef is a World Heritage site in the eastern Indian Ocean that comprises $>290 \mathrm{~km}$ of fringing coral reef encompassing a shallow lagoon dominated by $>30000$ hectares of brown macroalgal meadows dominated by tropical members of the canopy-forming genus Sargassum (Kobryn et al. 2013, Fulton et al. 2014). While the taxonomy of Sargassum remains to be fully resolved for this tropical region, our collections were focused on the most common morphotype in these meadows which we believe matches the description for Sargassum polycystum (Huisman 2019). For this study, which focused on spatial variation in the Sargassum epifaunal community, we selected 9 distinct Sargassum meadow patches separated by a minimum of $300 \mathrm{~m}$ and spread across the 3 distinct seascape positions of nearshore (sites typically within 50 to $300 \mathrm{~m}$ of the shoreline and embedded within ancient reef pavement covered in a layer of sand an average of $1-3 \mathrm{~cm}$ thick), lagoon (>500 m from shoreline and embedded within pavement-sand matrix) and back reef (embedded within pavementsand surrounded by fringing coral reef), within a $6 \mathrm{~km}^{2}$ section of the Maud Region of the Ningaloo Marine Park near Coral Bay, Western Australia (Fig. 1). These seascape positions are relevant to many coastlines where Sargassum meadows occur alongside coral reefs in the Pacific (e.g. New Caledonia), Indian (e.g. Ningaloo and Tanzania) and Atlantic (e.g. Brazil) Oceans, as well as the Red Sea (Berkström et al. 2013, Tano et al. 2016, Fulton et al. 2019). The macroalgal meadow study sites were an average of $26210 \mathrm{~m}^{2}( \pm$ $10605 \mathrm{~m}^{2} \mathrm{SE}$ ) in area (van Lier et al. 2018), embedded within a pavement-sand matrix in shallow water (2-6 $\mathrm{m}$ deep), and were subject to similar site-level mean sea temperatures $\left(27.3 \pm 0.1^{\circ} \mathrm{C}\right)$ during the $4 \mathrm{wk}$ field survey and collection period.

\subsection{Sargassum epifauna sampling}

During the late austral summer (February to March) of 2018, we collected 9 entire S. polycystum individuals and their epifauna at each of the 9 study 


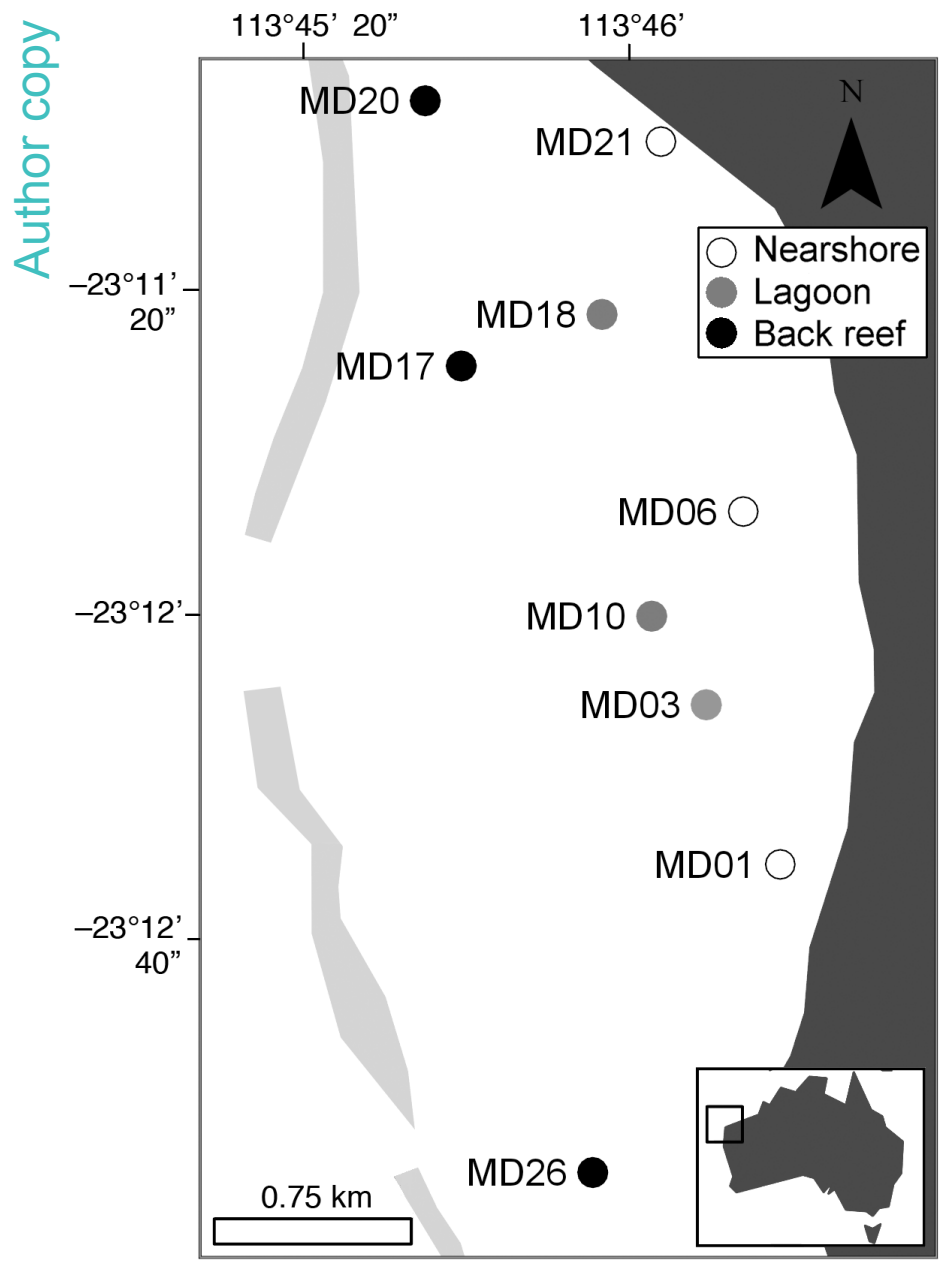

Fig. 1. Nine Sargassum-dominated study sites at 3 seascape positions (nearshore, lagoon, back reef) within the Maud Recreation Zone near Coral Bay, Ningaloo Reef, Western Australia

sites. Since canopy size can be a key predictor for epifaunal abundance (Edgar 1990b), we haphazardly sub-sampled a cross section of Sargassum canopy sizes at each site. To do this, a $15 \mathrm{~m}$ line transect across the centre of each study site was used to select the $S$. polycystum individuals closest to the $5 \mathrm{~m}$ mark that fell within each of 3 height classes $(>60,30-60$ and $<30 \mathrm{~cm})$. These height classes corresponded to the top, middle and bottom third of mean canopy sizes recently recorded for this region across sites, years and seasons (Wilson et al. 2014, van Lier et al. 2018). We repeated this procedure at the 10 and $15 \mathrm{~m}$ points on the same line transect to collect a total of $9 \mathrm{~S}$. polycystum individuals per site ( 3 per size class). For each selected $S$. polycystum individual, a SCUBA diver gently and fully enclosed the entire $S$. polycystum thallus and associated epifauna with a canvas bag, then cut the stipe just above the holdfast before immediately sealing the canvas bag to reduce the risk of epifauna escape. All collected samples were brought back to the research vessel within $30 \mathrm{~min}$ and transported in a cooler to the Coral Bay Research Station for processing within $4 \mathrm{~h}$ of collection.

Post-collection processing of $S$. polycystum individuals involved immersion in cold freshwater for 10 min before gently shaking and then dislodging all of the chilled epifauna from their $S$. polycystum host with a salad spinner. All of the cold freshwater containing the epifauna was then passed through a $125 \mu \mathrm{m}$ stainless steel sieve so the retained particles could be washed into a labelled zip bag and frozen at $-20^{\circ} \mathrm{C}$ for transport to The Australian National University for further analysis. After all the freshwater was removed from the $S$. polycystum individual, a range of metrics were taken for each host canopy: total extended length from stipe end to tip (to nearest $\mathrm{cm}$ ), total volume (to nearest millilitre measured via displacement of freshwater in a measuring cylinder) and total wet weight $(\mathrm{g})$. $S$. polycystum individuals were then dried in an oven at $60^{\circ} \mathrm{C}$ for $48 \mathrm{~h}$ to obtain a canopy dry weight (to nearest $0.1 \mathrm{~g}$ ).

Total abundance of epifauna collected from each $S$. polycystum individual was quantified by defrosting the epifauna and fixing them in a $10 \%$ formalin-seawater solution for $1 \mathrm{~h}$, before rinsing in seawater for identification and enumeration under a stereo-microscope with $40 \times$ magnification. To allow estimation of epifaunal biomass in terms of ash-free dry weight (AFDW), we used the sieve method proposed by Edgar (1990c), which involved passing the now-fixed epifauna samples through a nested series of sieves $(8.0,5.6,4.0,2.8,2.0,1.4,1.0,0.7$ and $0.5 \mathrm{~mm}$ stainless steel mesh sizes) that fractionated the epifauna by body size. Epifauna retained on each sieve were then identified to 6 taxonomic groups following Edgar (1990c): crustaceans, molluscs, echinoderms, polychaetes, foraminifera and other animals; epifaunal abundance was determined by counting all individuals per taxonomic group per sieve size. For epifauna retained on sieve sizes of $\leq 4.0 \mathrm{~mm}$, we used the empirically derived equations of Edgar (1990c) to estimate the total AFDW of each taxonomic group in the sample. For all epifauna $>5.6 \mathrm{~mm}$, we empirically measured the dry weight and ash weight of each taxonomic group (following $48 \mathrm{~h}$ in a $60^{\circ} \mathrm{C}$ oven or $2 \mathrm{~h}$ in a $500^{\circ} \mathrm{C}$ muffle furnace, respectively) to estimate AFDW by subtracting the ash weight from dry weight. 


\subsection{Macroalgal and invertivorous fish surveys}

Macroalgal benthic composition within each site was estimated underwater by SCUBA divers deploying 6 replicate $10 \mathrm{~m}$ line transects run in series and separated by a minimum of $5 \mathrm{~m}$. Along each transect, the relative percentage cover of macroalgal genera was estimated by recording the distance occupied under the line (to nearest $5 \mathrm{~cm}$ ). Sargassum canopy structure was also assessed in terms of holdfast density (number within a $0.5 \times 0.5 \mathrm{~m}$ quadrat) and vertical canopy height (maximum length when manually extended along a ruler to nearest $\mathrm{cm}$ ) at $2 \mathrm{~m}$ intervals (starting at $0 \mathrm{~m}$ ) to yield 6 replicate measures of each canopy metric per $10 \mathrm{~m}$ line transect, following Wilson et al. (2014).

Invertivorous fishes have been identified as common in tropical macroalgal meadows and include species in the 4 diverse families of the Labridae (excluding the Scarinae), Lethrinidae, Mullidae and Serranidae (Wilson et al. 2010, van Lier et al. 2018, Fulton et al. 2019). We estimated the biomass of these fish families within our 9 study sites using the pointcensus cylinder survey method of Noble et al. (2013). This involved the same observer on SCUBA recording the estimated total length $(\mathrm{cm})$ of all target fishes within 6 replicate $5 \mathrm{~m}$ diameter cylinders that were haphazardly spread within each site so as to be separated by at least $5 \mathrm{~m}$ from each other. Mean sitelevel biomass of each fish family was then calculated by converting the total length $(\mathrm{cm})$ of all individuals to an estimated mass ( $g$ ) using published lengthweight relationships for each species (Kulbicki et al. 2005, Froese \& Pauly 2019).

\subsection{Data analyses}

To examine which measures of Sargassum canopy size may best predict variation in epifaunal total abundance and biomass, we used least-squares regression to model the relationships between 3 metrics of Sargassum canopy size (total length, volume and dry weight) and either total epifaunal abundance or total epifaunal biomass (AFDW) per S. polycystum individual. Initial analyses indicated that most relationships were significant and non-linear (see Fig. A1 in the Appendix), so they were linearised via natural log-log transformations for subsequent analyses.

Epifaunal community structure among sites was then explored in terms of both individual abundance and biomass of the 6 taxonomic groups of epifauna (as dependent variables), with the fixed factor of sea- scape position (nearshore, lagoon or back reef) and random factor of site (nested in seascape position) in a 2-way multivariate permutational analysis of covariance (PERMANCOVA). Sargassum canopy size was included as a covariate (logged volume for epifaunal abundance, logged dry weight for epifaunal biomass). These PERMANCOVAs were performed with Type 1 sum of squares and a maximum of 9999 permutations of resemblance matrices based on the modified Gower (base 2) dissimilarity measure applied to either $\log _{10}(x+1)$ (abundance) or fourth-root (biomass) transformed data that were used to reduce skew across the dependent variables (Anderson et al. 2006, 2008). Post-hoc explorations of significant terms were explored with threshold-metric multidimensional scaling (tmMDS) ordinations of the siteseascape group centroids. Ordination structure in epifaunal individual abundance and biomass was explored with principal components analysis (PCA), optimised with vector overlays to indicate the degree of Pearson's correlation between the epifaunal variables and the ordination structure.

Possible environmental predictors of site-level variation in the relative biomass of the 6 taxonomic groups of Sargassum epifauna were explored with best-subsets model selection using distance-based linear models (DistLM) and the Akaike information criterion corrected for finite sample sizes (AICc) to select the most parsimonious model(s), following Burnham \& Anderson (2002). We first converted the matrix of dependent data (being epifaunal biomass per taxonomic group) into biomass per Sargassum canopy dry weight (mg epifauna $\mathrm{g} \mathrm{DW}^{-1}$ ) to take account of general canopy size effects on epifaunal biomass. This standardised epifaunal biomass was then arranged into a modified Gower (log base 2) resemblance matrix, following a fourth-root transformation to correct for skew. An environmental predictor matrix was assembled, comprising site means for 3 groups of possible predictors: invertivorous fish biomass (per each of the 4 families), Sargassum canopy structure (canopy height, holdfast density, percent cover canopy and understory taxa, taxonomic genera richness and Pielou's evenness) and seascape context (meadow patch area, distance to fringing reef, distance to nearest neighbouring meadow and depth). The most parsimonious environmental model for predicting Sargassum epifaunal biomass across the 9 study sites was chosen as the one with the fewest variables within 2 AICc of the top model, which was then visualised by a distance-based redundancy analysis (dbRDA) ordination with the best predictor environmental vectors as an overlay. All 
analyses were performed in PRIMER (v.7.0.13) with the Permanova+ add-on (Anderson et al. 2008).

\section{RESULTS}

A total of 49431 epifauna individuals were extracted from $81 S$. polycystum individuals, which represented an estimated total biomass of $18619.4 \mathrm{mg}$ (AFDW) of epifauna from $6119.8 \mathrm{~g}$ (dry weight) of tropical Sargassum canopy biomass. Total abundance and biomass of epifauna per $S$. polycystum individual varied significantly with all 3 measures of Sargassum canopy size (Fig. 2). Pearson's correlation was highest for epifaunal abundance against Sargassum canopy volume (Fig. 2B); correlations were generally lower for epifaunal biomass-canopy relationships, being highest for Sargassum canopy dry weight (Fig. 2F).

Half of the total epifaunal abundance (50.0\%) consisted of crustaceans (mainly Amphipoda, Har- pacticoida and Isopoda), a third (33.4\%) were molluscs (mainly Gastropoda), and the remainder comprised foraminifera $(9.1 \%)$, echinoderms $(2.6 \%$, mostly Ophiuroidea), polychaetes (1.9\%) and a mixture of other animals $(2.7 \%$, including Nematoda). In biomass terms (estimated as AFDW that excludes skeletal tissues such as shells), however, molluscs were the dominant group ( $77 \%$ of the overall total), followed by crustaceans $(20 \%)$. Considerable variation was apparent at the sample level, with little apparent structure in either epifaunal abundance or biomass as related to seascape position across all of the taxonomic groups (Figs. $3 \& 4$ ), perhaps with the exception of crustaceans and molluscs being more abundant in the back reef $S$. polycystum samples (Fig. 3A,B) that also tended to be at the larger end of the canopy size spectrum across the entire collection (Fig. 2A-C).

Both epifaunal individual abundance and biomass varied significantly among sites, with a significant
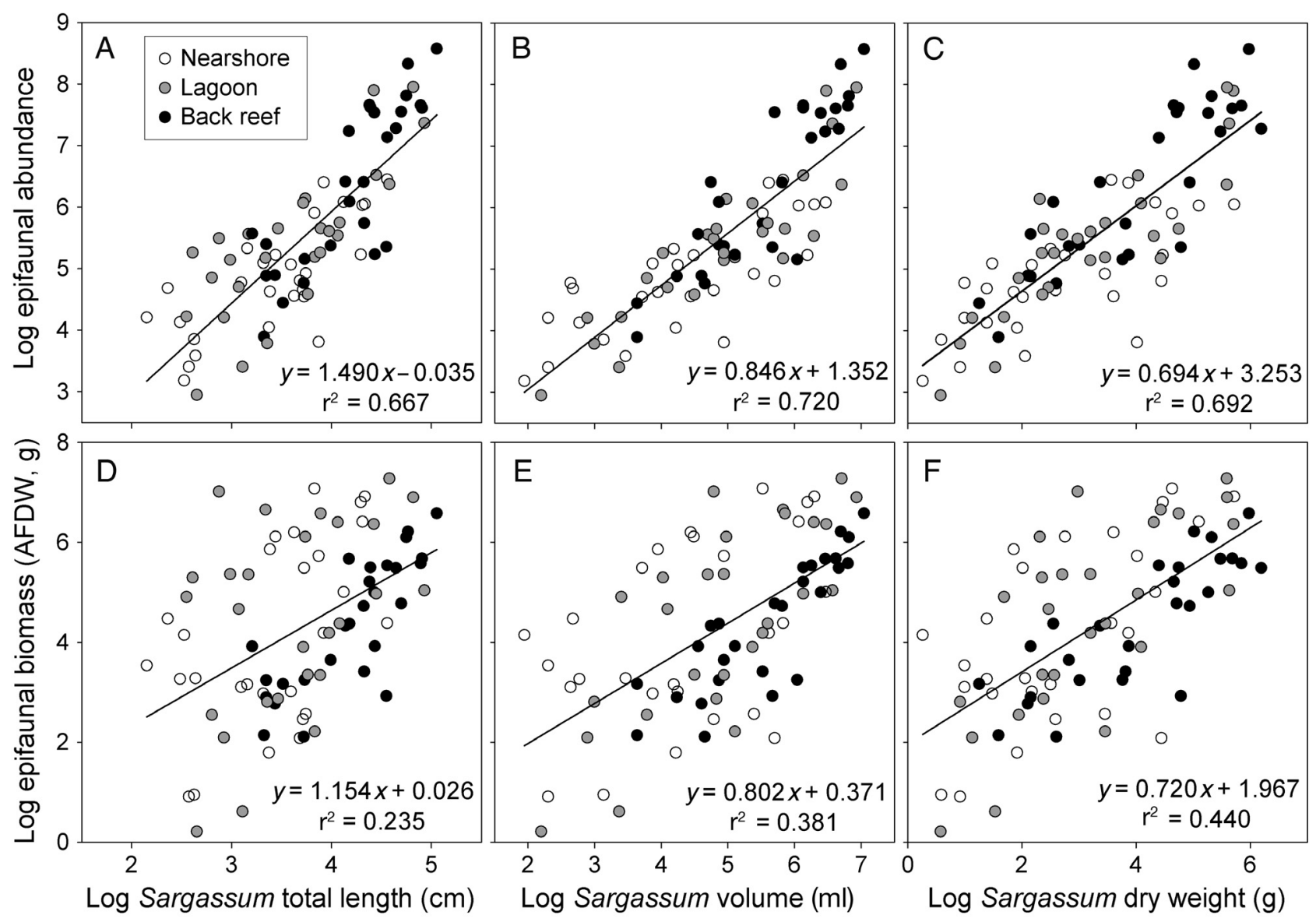

Fig. 2. Log-log plots of the relationship between different measures of Sargassum canopy size (total length, volume, and dry weight) and either (A-C) epifaunal abundance (total individuals per $S$. polycystum) or (D-F) epifaunal biomass (ash-free dry weight, AFDW, per $S$. polycystum) collected from 9 study sites at 3 seascape positions (nearshore, lagoon, and back reef) in the Maud region of Ningaloo Reef during summer 2018 


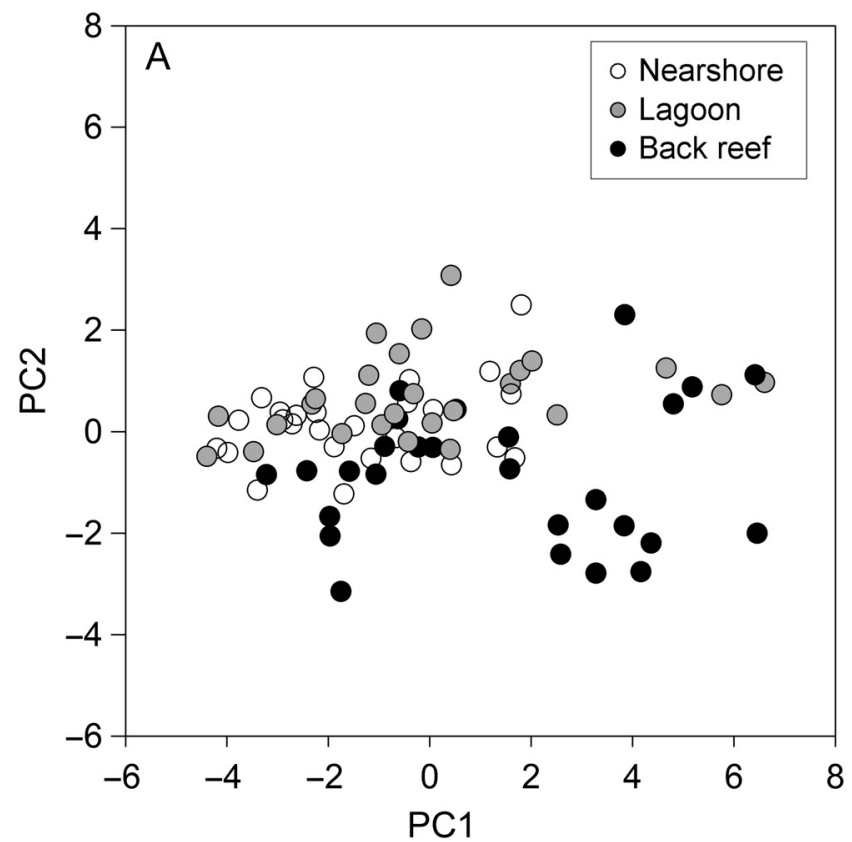

B

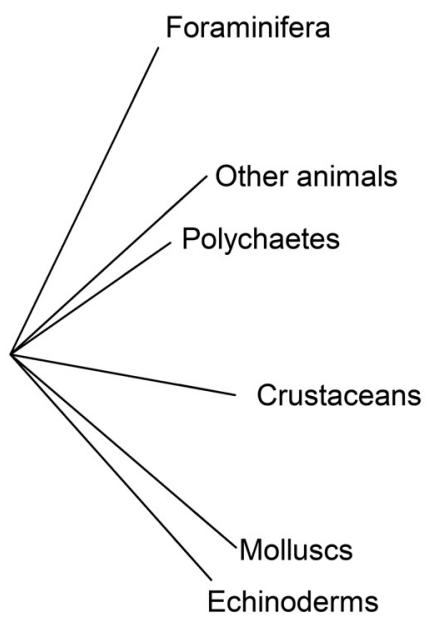

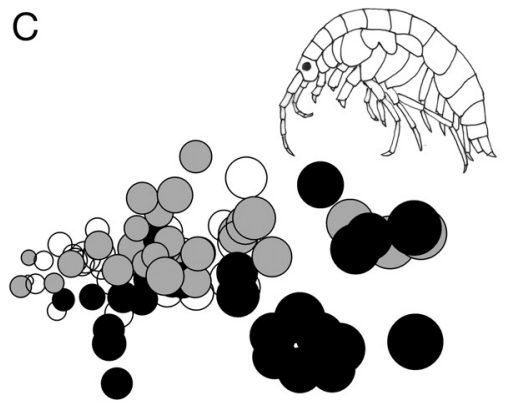

Crustaceans

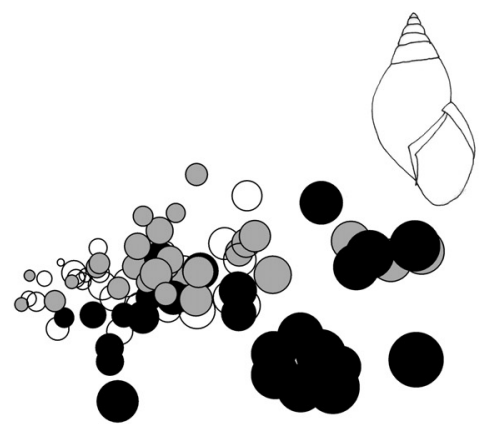

Molluscs

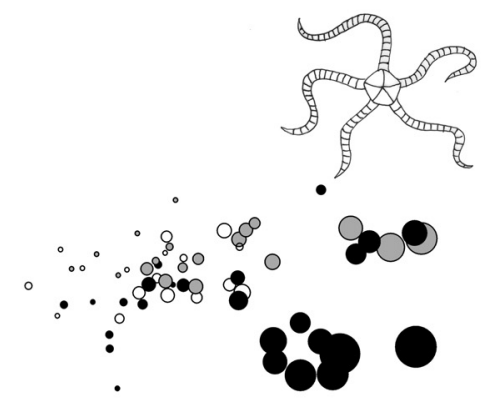

Echinoderms

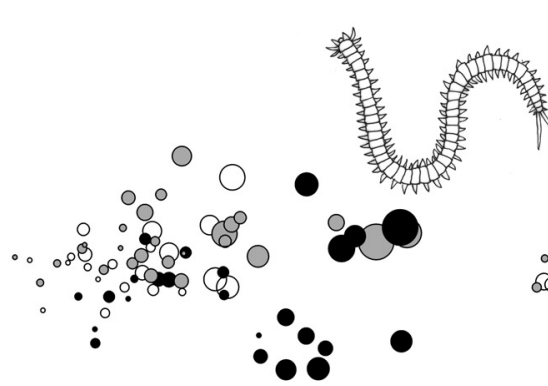

Polychaetes

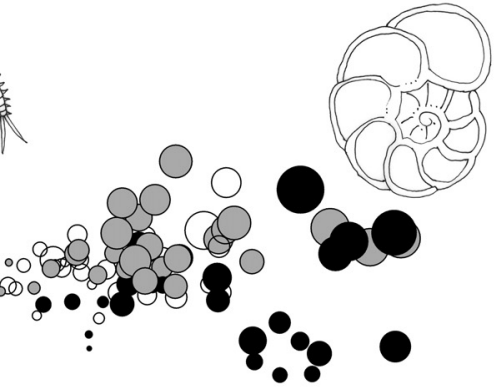

Foraminifera

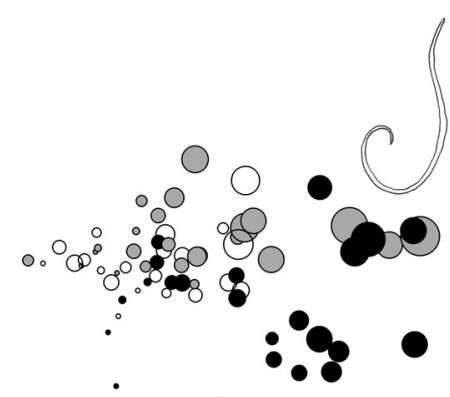

Other animals

Fig. 3. Principal component analysis (PCA) of epifaunal abundance on 81 individual $S$. polycystum collected from 9 sites (n $=9$ samples per site) at 3 seascape positions (nearshore, lagoon, and back reef; $\mathrm{n}=3$ sites per position) in Ningaloo during summer 2018. (A) Total epifaunal abundance, and (B) vector overlay of epifaunal taxonomic groups strongly correlated with the ordination structure, and (C) ordinations optimised with bubbles scaled to relative abundance of each epifaunal group

interaction between Sargassum canopy size and seascape position after taking into account the significant covariance between canopy size and epifauna (Table 1, Fig. 2). Whilst the largest Sargassum canopy sizes were sampled in the back reef, there was high variability among sites that created considerable overlap among all 3 seascape positions (Fig. 5). Focusing on this site-level variation, bestsubsets model selection revealed 2 competing models that could provide the best predictors for epifau- 


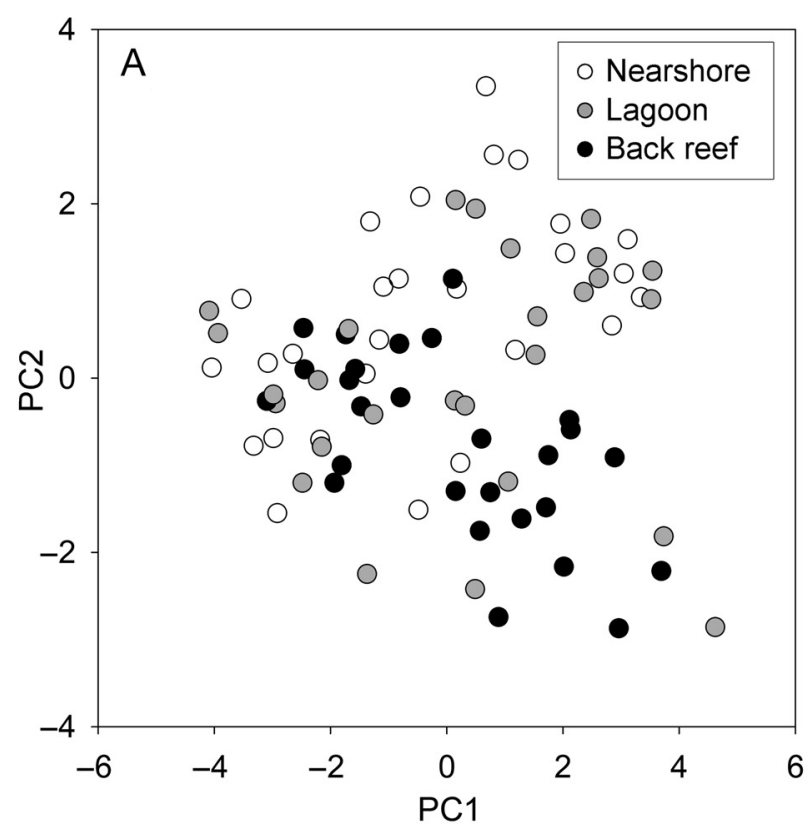

C

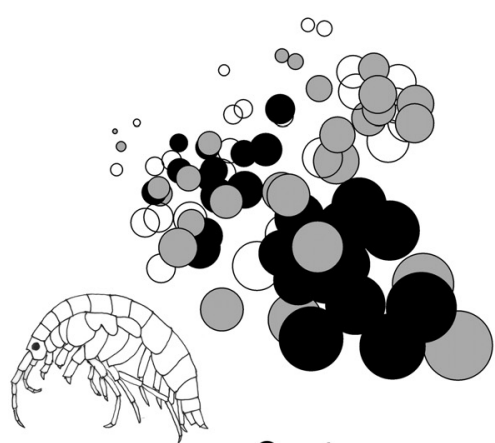

Crustaceans

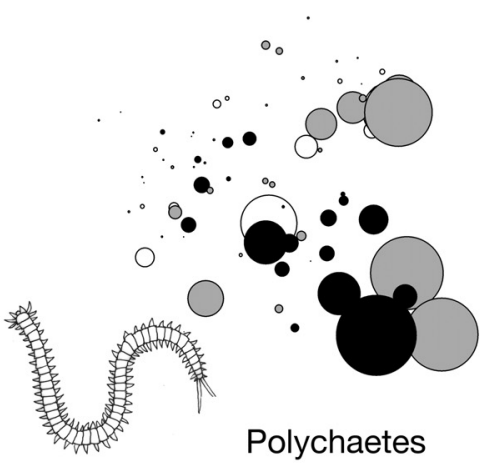

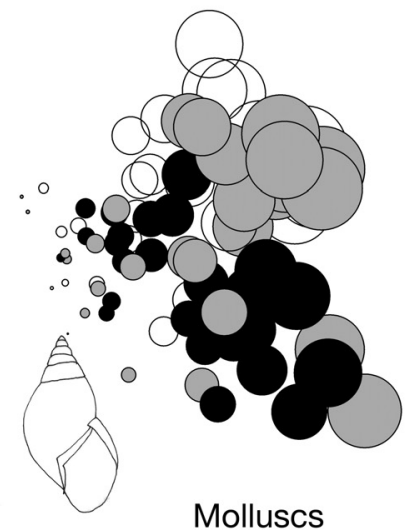

Molluscs

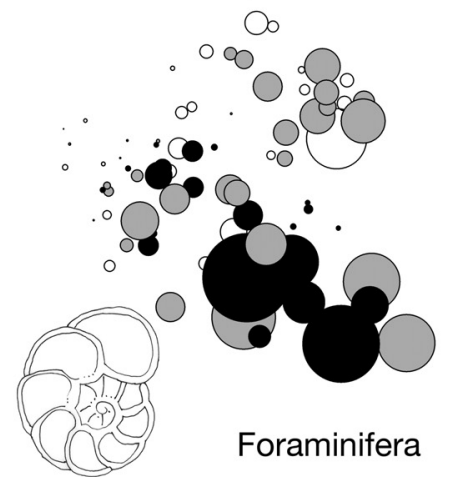

B

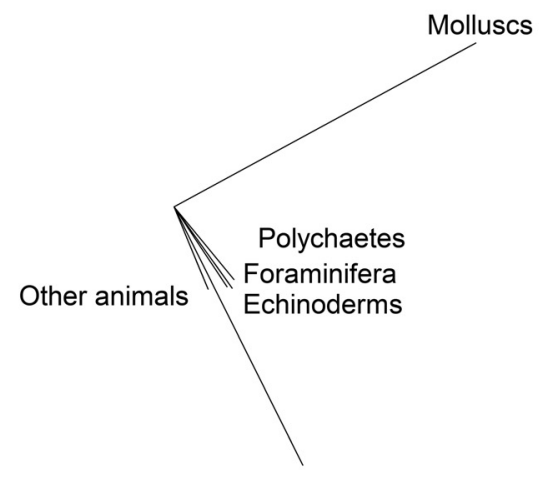

Crustaceans
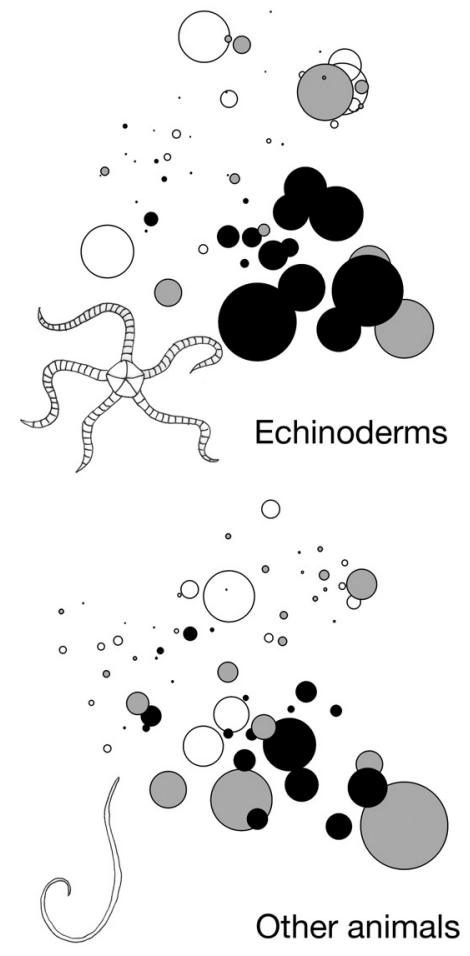

Fig. 4. PCA of epifaunal biomass on 81 individual $S$. polycystum collected from 9 sites (n = 9 samples per site) at 3 seascape positions (nearshore, lagoon, and back reef; $\mathrm{n}=3$ sites per position) in Ningaloo during summer 2018. (A) Total epifaunal biomass, and (B) vector overlay of epifaunal taxonomic groups strongly correlated with the ordination structure, and (C) ordinations optimised with bubbles scaled to relative biomass of each epifaunal group

nal community biomass structure (Table 2), which were based on either invertivorous fish biomass (Fig. 6A,C) or seascape context (Fig. 6B,D). In general, Sargassum at sites characterised by a high biomass of mullid fishes had higher epifaunal biomass for a given canopy size, while a lower epifaunal biomass (particularly molluscs; Fig. 6C) tended to be found in sites characterised by a high biomass of labrid, serranid and lethrinid fishes (Fig. 6A,C). Distance to fringing reef was the best single seascape 
Table 1. Summary of PERMANCOVA of Sargassum epifaunal (A) individual abundance and (B) biomass across 3 seascape positions (fixed) and 9 study sites (random, nested in seascape) in the Maud region of Ningaloo Reef during summer 2018, with log Sargassum canopy size included as a covariate in terms of either (A) volume or (B) dry weight according to the best predictors for the canopy size-epifauna relationships (see Fig. 2). Significant terms $(p<0.05)$ are highlighted in bold

\begin{tabular}{|lrrrrc|}
\hline Source & df & \multicolumn{1}{c}{ SS } & MS & Pseudo- $F$ & p-value \\
\hline (A) Epifaunal individual abundance & & & & & \\
Sargassum canopy volume & 1 & 16.125 & 16.125 & 55.990 & $<\mathbf{0 . 0 1}$ \\
Seascape & 2 & 1.139 & 0.569 & 1.024 & 0.454 \\
Site (Seascape) & 6 & 3.445 & 0.574 & 3.064 & $<\mathbf{0 . 0 1}$ \\
Sargassum & 2 & 1.129 & 0.564 & 3.012 & $<\mathbf{0 . 0 5}$ \\
$\quad$ canopy volume $\times$ Seascape & & & & & \\
Sargassum canopy volume $\times$ Site & 6 & 1.812 & 0.302 & 1.612 & 0.079 \\
Residual & 63 & 11.807 & 0.187 & & \\
Total & 80 & 35.456 & & & \\
(B) Epifaunal biomass & & & & & \\
Sargassum canopy dry weight & 1 & 13.127 & 13.127 & 18.134 & $<\mathbf{0 . 0 1}$ \\
Seascape & 2 & 1.865 & 0.932 & 0.506 & 0.827 \\
Site (Seascape) & 6 & 11.365 & 1.894 & 4.873 & $<\mathbf{0 . 0 1}$ \\
Sargassum canopy & 2 & 2.817 & 1.409 & 3.623 & $<\mathbf{0 . 0 1}$ \\
$\quad$ dry weight $\times$ Seascape & & & & & \\
Sargassum canopy & 6 & 3.301 & 0.550 & 1.415 & 0.115 \\
$\quad$ dry weight $\times$ Site & & & & & \\
Residual & 63 & 24.491 & 0.389 & & \\
Total & 80 & 56.967 & & & \\
\hline
\end{tabular}

\section{DISCUSSION}

Our study found 3 key results that significantly increased our understanding of invertebrate biodiversity patterns within tropical seascapes containing macroalgal meadows. First, we found an overarching positive correlation between epifaunal community structure and Sargassum canopy size, although the best canopy size metric varied for the measures of epifaunal individual abundance and biomass. Second, we found epifaunal community structure varied significantly among Sargassum meadow patches, with a prominent interaction between host canopy size and seascape position. Third, the local biomass of invertivorous fish and the position of macroalgal meadows within the seascape provided some of the best predictors for site-level variations in Sargassum predictor for epifaunal community structure (accounting for $>47 \%$ of the total variation along dbRDA1), with a trend of increasing epifaunal biomass (particularly molluscs) with increasing distance of the patch from the coral back reef (Fig. 6B). Depth and distance to the nearest neighbouring Sargassum meadow appeared to play a smaller overall role ( $8 \%$ of total variation along dbDRA2) in explaining spatial variations in epifaunal canopyspecific biomass (Fig. 6B,D).

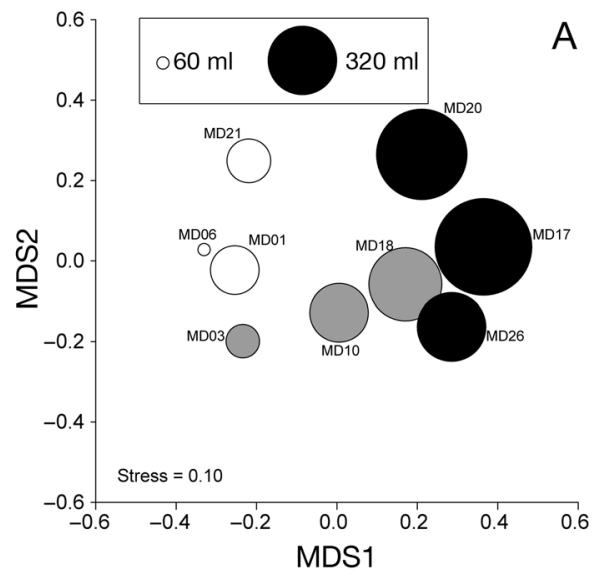

Table 2. Summary of best-subsets selection of distancebased linear models for predicting site-level variation in biomass of Sargassum epifauna. The most parsimonious models within 2 Akaike information criterion (AICc) units of the top model are indicated in bold

\begin{tabular}{|lrcc|}
\hline Model & AICC & deltaAICc & $\mathrm{r}^{2}$ \\
\hline Invertivorous fish biomass & $\mathbf{2 . 4 1 3}$ & - & $\mathbf{0 . 6 3 5}$ \\
Seascape context & $\mathbf{3 . 1 0 3}$ & $\mathbf{0 . 6 9}$ & $\mathbf{0 . 6 0 6}$ \\
Canopy structure & 88.001 & 85.59 & 0.885 \\
\hline
\end{tabular}

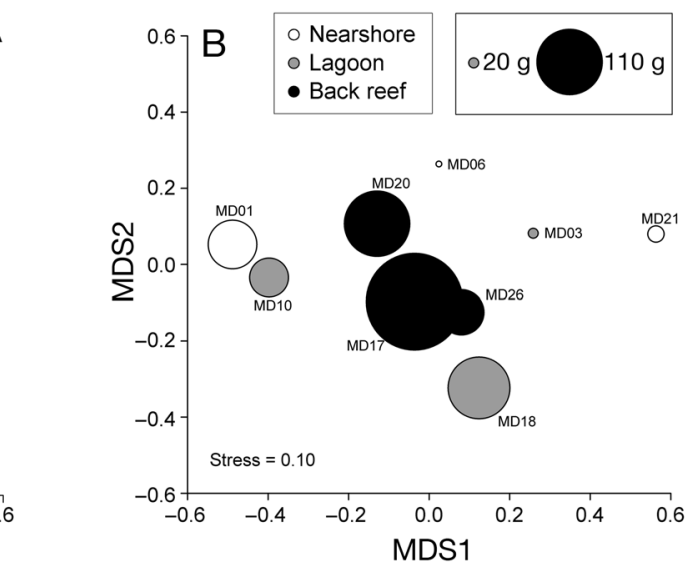

Fig. 5. Threshold-metric multi-dimensional scaling (tmMDS) ordination of site-level group centroids for Sargassum epifaunal (A) abundance and (B) biomass collected at 3 seascape positions (nearshore, lagoon, back reef; $\mathrm{n}=3$ sites per position) within Ningaloo during summer 2018. Bubble sizes are proportional to site-level mean Sargassum canopy (A) volume or (B) dry weight to explore the significant canopy seascape interaction (see Table 1) 
epifaunal community structure (Fig. 7). Given that epifauna are a critical trophic link between the macroalgal production base and higher-order consumers such as fishes, our evidence suggests distinct differences in the trophodynamics of these tropical ecosystems across relatively fine spatial scales
$(<2 \mathrm{~km})$. Moreover, the strong links between epifaunal biomass and canopy size, and the sensitivity of Sargassum canopy growth to sea temperature (Fulton et al. 2014, 2019), suggest climate change is likely to influence flows of primary to secondary production in macroalgae-dominated systems.
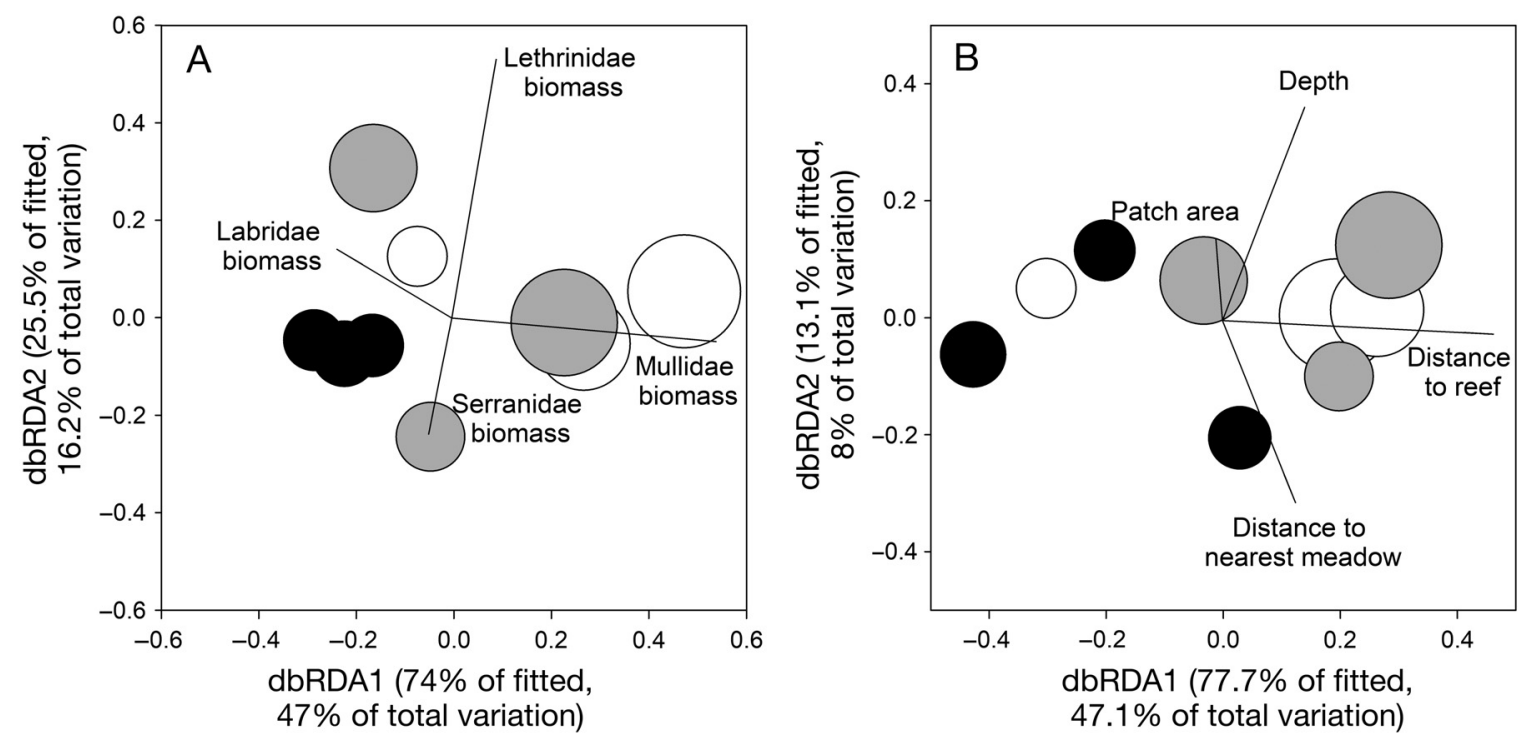

\section{C}

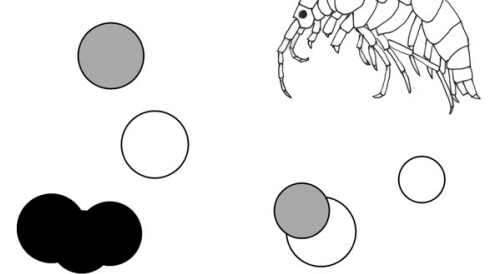

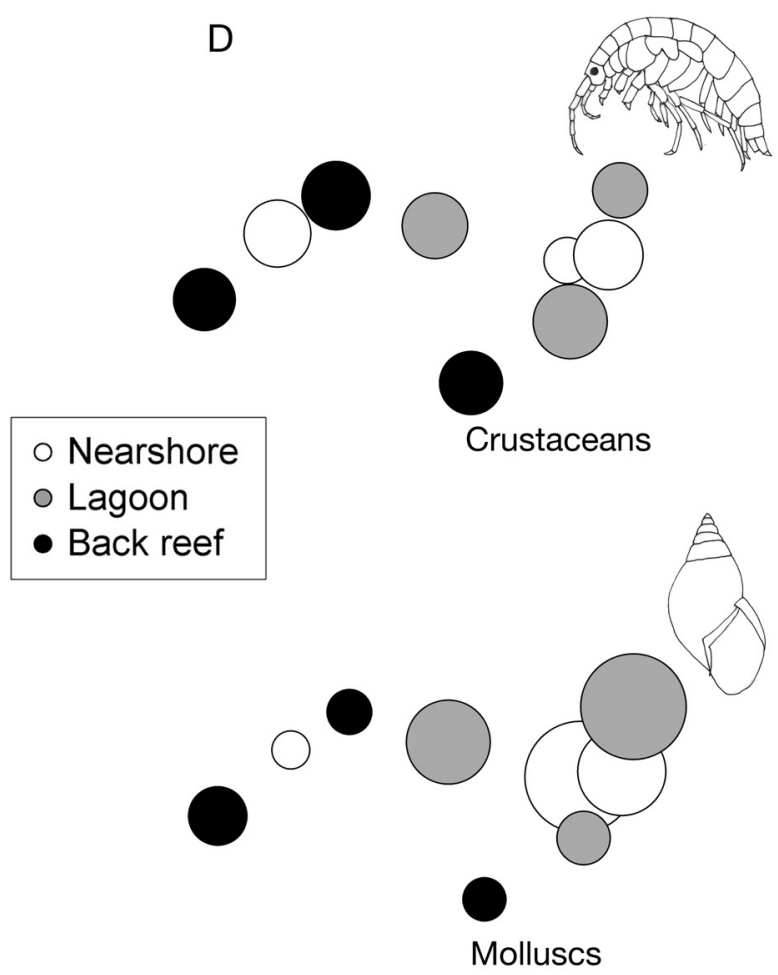

Fig. 6. Distance-based redundancy analysis (dbRDA) ordination of the most parsimonious best-subsets models for predicting site-level variation in epifaunal biomass across 3 seascape positions (nearshore, lagoon and back reef) in terms of (A) invertivorous fish biomass and (B) seascape context, with optimisations showing bubble sizes scaled to site-level epifaunal biomass for both crustacea and molluscs for each model (C and D, respectively). Vector overlays indicate invertivorous fish family and seascape metric most strongly correlated with each ordination structure 


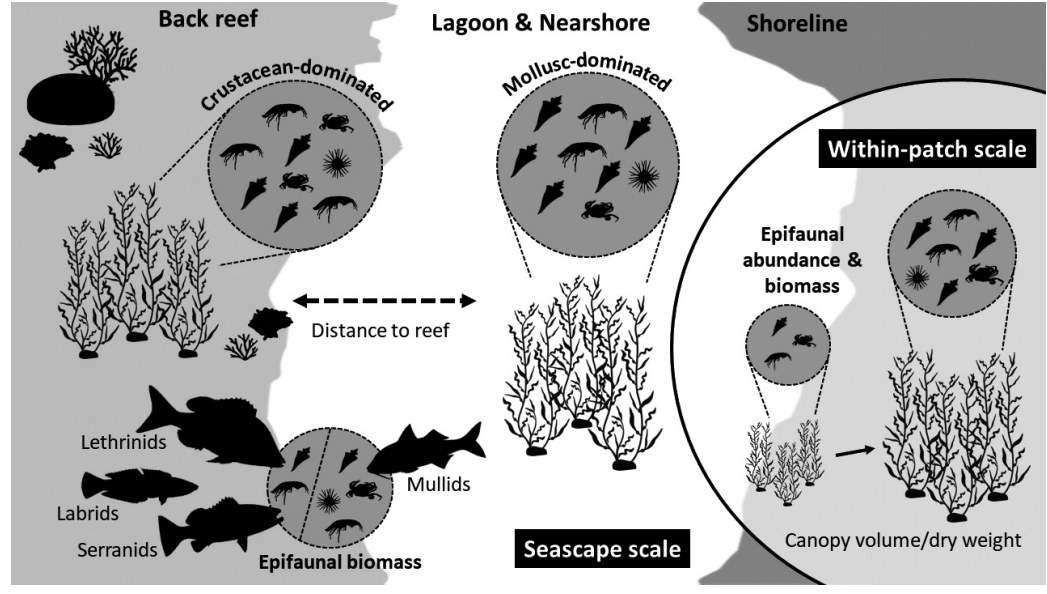

Fig. 7. Conceptual diagram showing the relationship between macroalgal canopy volume/dry weight and epifaunal abundance/biomass at within-patch scale, and how seascape contexts and the presence of invertivorous fishes affect epifaunal community structure at seascape scales

ples, which is consistent with prior studies of epifaunal biomass on tropical and temperate Sargassum (Mukai 1971, Edgar \& Aoki 1993, Edgar \& Klumpp 2003, Leite \& Turra 2003). Notably, Pearson's correlations for epifaunal biomass-canopy relationships were generally lower than for epifaunal abundance-canopy relationships, which may arise from biomass estimates of epifauna larger than $5.6 \mathrm{~mm}$ that represent a greater amount of biomass $(59.14 \%)$ relative to their individual abundance $(0.86 \%)$ of the total epifaunal community. Nonetheless, we found significant positive correlations between the amount of epifauna and Sargassum canopy size, which is emerging as a common scenario in

Strong correlations between epifaunal abundance and Sargassum canopy size, such as those found in this study, may arise through habitat amount effects that can govern the size and diversity of ecological communities (Fahrig 2013). However, the differing metrics of canopy size relevant to either individual abundance or biomass of epifauna suggest some nuanced effects related to habitat microstructure. For instance, epifaunal abundance was most strongly correlated with canopy volume (rather than canopy length or biomass), which may point to the importance of overall surface area and microniches for colonisation by mobile animals on fresh Sargassum (Carvalho et al. 2018). Indeed, canopy macroalgal meadows have already been found to harbour more epifauna than other macrophyte habitats, such as seagrass meadows (Tano et al. 2016, Belattmania et al. 2018), the epilithic algal matrix (EAM; Kramer et al. 2012, 2014) or the understory macroalgae (Wenger et al. 2018), due to their complexity and higher volumetric canopy structure. An increased epiphyte load, which increases the structural complexity and surface area of the overall macroalgal canopy, has also been found to support a greater abundance of epifauna (Martin-Smith 1993, Leite \& Turra 2003). Our late-summer samples at Ningaloo showed a very low occurrence level of S. polycystum epiphytes (total of $53.65 \mathrm{~g}$ epiphytes across $6119.8 \mathrm{~g} S$. polycystum, dry weight). Epiphyte loads on tropical Sargassum can change dramatically with season (Martin-Smith 1993, Lefevre \& Bellwood 2010), and such seasonal effects should be a priority for future research in this area. We found epifaunal biomass, however, was most strongly correlated with Sargassum canopy dry weight in the Ningaloo sam- tropical Sargassum communities (Martin-Smith 1993, Wenger et al. 2018).

Epifaunal communities inhabiting Sargassum canopies in Ningaloo were dominated by 2 key taxonomic groups: crustaceans and molluscs. Peracarid crustaceans (amphipods and isopods), harpacticoid crustaceans and gastropod molluscs were the main taxonomic groups contributing to total epifaunal abundance (83.4\%) and biomass (94\%), followed by ophiuroid echinoderms and polychaetes. Our findings are congruent with previous studies indicating that crustaceans and molluscs are the most abundant mobile epifauna on Sargassum in tropical and temperate biomes around the world (Table 3). Indeed, studies of epifauna living within turf algae of the EAM (immediately adjacent to corals) or scleractinian corals found crustaceans were most abundant, followed by molluscs, annelids, foraminifera, and nematodes (Stella et al. 2010, Kramer et al. 2012, Kramer et al. 2014). Depending on seascape setting (explored further below), these 2 taxonomic groups may be the most abundant drivers of trophodynamics and nutrient cycling within these macroalgal-dominated ecosystems. Notably, our estimates of total epifaunal density (individual number per g Sargassum dry weight) were $\sim 3$-fold lower than the average from other studies of tropical and temperate Sargassum epifauna (Table 3). A previous estimate from a single Sargassum meadow at Ningaloo, which was an order of magnitude higher than our estimate (148 individuals per $g$ canopy dry weight; Wenger et al. 2018), provides some insight into the possible source of these differences. Wenger et al. (2018) used $0.12 \mathrm{~mm}$ as the finest mesh size while processing 
Table 3. Studies of Sargassum-associated epifaunal composition around the world. Epifaunal density is presented as the individual number per gram of Sargassum dry weight. The top 3 most abundant taxa (if present) are listed. Most studies used a $0.5 \mathrm{~mm}$ mesh size, and studies using 0.1 to $0.3 \mathrm{~mm}$ mesh size are marked with an asterisk. Sargassum wet weight in some studies was converted to dry weight by following Brey et al. (2010)

\begin{tabular}{|c|c|c|c|}
\hline $\begin{array}{l}\text { Epifaunal } \\
\text { density }\end{array}$ & Most abundant taxa & Focal region & Source \\
\hline \multicolumn{4}{|c|}{ (A) Tropical } \\
\hline 13 & Crustaceans $>$ Molluscs $>$ Foraminifera & Ningaloo Reef, Australia $\left(23^{\circ} 1^{\prime} \mathrm{S}\right)$ & Present study \\
\hline 8 & Crustaceans > Molluscs > Polychaetes & Northeast Queensland, Australia $\left(18^{\circ} 1^{\prime}-18^{\circ} 4^{\prime} \mathrm{S}\right)$ & Edgar \& Klumpp (2003) \\
\hline $31^{*}$ & Crustaceans $>$ Polychaetes $>$ Molluscs & The Great Barrier Reef, Australia (19²'S) & Martin-Smith (1993) \\
\hline 12 & Crustaceans $>$ Molluscs $>$ Polychaetes & Red Sea, Saudi Arabia $\left(21^{\circ} 2^{\prime} \mathrm{N}\right)$ & Ba-Akdah et al. (2016) \\
\hline $148^{*}$ & Foraminifera $>$ Crustaceans $>$ Molluscs & Ningaloo Reef, Australia (231' S) & Wenger et al. (2018) \\
\hline $66^{*}$ & Molluscs $>$ Crustaceans $>$ Polychaetes & Flamengo Bay, Brazil $\left(23^{\circ} 3^{\prime} \mathrm{S}\right)$ & Leite \& Turra (2003) \\
\hline 1 & Crustaceans $>$ Polychaetes $>$ Molluscs & Lazaro and Tabatinga, Brazil $\left(23^{\circ} 3^{\prime} \mathrm{S}\right)$ & Tanaka \& Leite (1998) \\
\hline \multicolumn{4}{|c|}{ Mean density \pm SE: $39.9 \pm 19.8$} \\
\hline \multicolumn{4}{|c|}{ (B) Temperate } \\
\hline 97 & Crustaceans $>$ Platyhelminthes $>$ Molluscs & Tomioka Peninsula, Japan $\left(32^{\circ} 3^{\prime} N\right)$ & Edgar \& Aoki (1993) \\
\hline 4 & Crustaceans $>$ Molluscs $>$ Polychaetes & El Jadida shoreline, Morocco $\left(33^{\circ} 2^{\prime} \mathrm{N}\right)$ & Belattmania et al. (2018) \\
\hline $74^{*}$ & Crustaceans $>$ Polychaetes $>$ Molluscs & Sydney \& Illawarra, Australia $\left(34^{\circ} 2^{\prime}-34^{\circ} 4^{\prime} \mathrm{S}\right)$ & Lanham et al. (2015) \\
\hline $3^{*}$ & Crustaceans $>$ Molluscs $>$ Annelids & Southeast New South Wales, Australia $\left(34^{\circ} 3^{\prime}-34^{\circ} 8^{\prime} \mathrm{S}\right)$ & Marzinelli et al. (2016) \\
\hline 31 & Molluscs > Crustaceans & West and south coast, Portugal $\left(37^{\circ} 1^{\prime}-37^{\circ} 4^{\prime} \mathrm{N}\right)$ & Engelen et al. (2013) \\
\hline 14 & NA & North coast, Portugal $\left(41^{\circ} 4^{\prime}-41^{\circ} 5^{\prime} \mathrm{N}\right)$ & Veiga et al. (2014) \\
\hline 2 & Crustaceans $>$ Molluscs $>$ Polychaetes & Galician coast, Spain $\left(42^{\circ} 1^{\prime}-42^{\circ} 2^{\prime} \mathrm{N}\right)$ & Gestoso et al. (2012) \\
\hline 6 & Molluscs $>$ Crustaceans $>$ Nematodes & Galician coast, Spain $\left(42^{\circ} 2^{\prime} N\right)$ & Gestoso et al. (2010) \\
\hline \multicolumn{4}{|c|}{ Mean density \pm SE: $28.9 \pm 13.0$} \\
\hline
\end{tabular}

their Sargassum epifauna, which captured an extremely abundant foraminifera fauna that were subsequently found to not be major prey targets for a Sargassum-associated invertivorous fish (Wenger et al. 2018). While there are some wide variations across studies using similar mesh collection sizes, there is a generally higher mean epifaunal density on tropical versus temperate Sargassum (Table 3). This fits with the notion that production of the ectothermic epifaunal community is higher in warmer sea temperatures (Edgar 1990c).

Consumers can exert strong top-down pressure on prey to shape relative abundance and biomass across space and time. Macroalgal meadows can be important foraging grounds for invertivorous fishes (Edgar \& Aoki 1993, Wilson et al. 2014, Tano et al. 2016), which have been found to specifically target mobile epifauna on macroalgae like Sargassum (Edgar \& Aoki 1993, Wenger et al. 2018), with varying effects. For instance, one study found no significant decrease in epifaunal abundance on Sargassum canopies caged to exclude fish foraging activity (Martin-Smith 1993). In contrast, Edgar \& Aoki (1993) found that predation by an invertivorous wrasse (Labridae) tended to remove larger epifauna from macroalgae in mesocosm experiments, which freed up resources (through competitive release) for smaller epifauna that subsequently increased in abundance. In other words, it appears predation could drive an increase in the abundance and productivity of Sargassum mobile epifauna, which may help explain why higher epifaunal biomass was often found in meadows with greater invertivorous fish biomass at Ningaloo. The biomass of common invertivorous fish species has been positively correlated to Sargassum canopy structure (Wilson et al. 2014, Wenger et al. 2018), with at least one invertivorous fish species found to preferentially target epifaunal crustaceans and molluscs on tropical Sargassum (Wenger et al. 2018). Given that invertivorous fishes have previously been shown to vary in abundance with seascape position (van Lier et al. 2018), some of the seascape effects on epifauna condition may arise from these predation effects. Such linkages of invertivorous fishes, epifauna and Sargassum in Ningaloo provide a hint of how secondary and higher production may be supported by the underlying Sargassum canopy habitat at Ningaloo and across seascapes dominated by Sargassum meadows around the world (Fulton et al. 2019). This is clearly a key research front for future work in this arena, requiring empirical study of epifauna-fish interactions and microhabitat foraging preferences to help resolve the relative importance of bottom-up (canopy structure) and top-down influences on macroalgal epifauna. 
Our study reveals that local conditions of mean Sargassum canopy size can vary considerably over fine spatial scales to provide one of the primary explanations (indicated by the significant interaction term) for variations in epifaunal community structure in a range of seascape contexts. At Ningaloo, Sargassum canopy size was not consistent across all meadows, creating a complex mosaic of high/low canopy density, height and cover across meadows spread across the seascape (Wilson et al. 2014, Lim et al. 2016, Wenger et al. 2018). While this was largely irrespective of seascape position, we did find a tendency for higher maximum Sargassum canopy size in back reef positions, where the Sargassum meadows were embedded among the fringing coral reef. Once these canopy size effects were taken into account, however, seascape position did provide further explanations for spatial variations in Sargassum epifaunal community structure. In particular, distance to the back reef provided one of the key predictors for differences in epifaunal community structure at Ningaloo. This was largely because of a shift in the relative dominance of the 2 major epifaunal taxa: crustaceans dominated the Sargassum epifauna in macroalgal meadows close to coral reef (i.e. back reef sites), while epifaunal molluscs predominated in nearshore and lagoonal macroalgal meadows. This is significant because these 2 invertebrate groups may have very different levels of growth (secondary production) to support consumption by higher-order consumers like fishes using different strategies for consumption and processing of these 2 prey types (Wainwright 1988, Edgar 1990a,b,c, Kramer et al. 2015). If so, then adjacent macroalgal meadows separated by relatively fine spatial scales (100s of metres to a few kilometres) may have remarkably different trophodynamics.

Strong canopy-epifauna relationships such as those revealed here indicate some broader consequences for the conservation and management of diverse and productive tropical seascapes. Across the range of canopy sizes examined here, which span a typical range of Sargassum canopy sizes that have been observed across sites, seasons and years in this region (Wilson et al. 2014, van Lier et al. 2018), we can see that even small reductions in canopy extent can translate to much lower epifaunal abundance with flow-on effects for associated species and overall ecosystem function. A reduction in Sargassum canopy from disturbance or seasonal effects is likely to trigger a trophic cascade in reduced productivity at higher trophic levels, with variable consequences across the seascape. The non-linear nature of these effects suggests a particularly severe reduction in epifaunal abundance for canopies below 30 to $60 \mathrm{~cm}$ height at Ningaloo. Indeed, similar reductions in canopy size due to seasonal cycles in Sargassum phenology have been linked to major declines in the abundance of macroalgal-dependent fishes (Lim et al. 2016, Wenger et al. 2018). Besides a reduction in the overall abundance of epifauna with canopy reductions, there may also be a loss of certain taxa (e.g. shifts in the gammarid crustacean epifauna over seasonal Sargassum canopy cycles; Kodama et al. 2020) that are key components in nutrient cycling and trophic flows. A major cause for concern is that one of the key stressors of climate change-sea temperature - is a primary determinant of Sargassum canopy growth in tropical reef settings around the world (Fulton et al. 2019). Alongside disturbances like marine heatwaves and cyclones (Fulton et al. 2019) which can dramatically reduce Sargassum canopy size in a short time, these climatic effects can drive a bottom-up collapse of trophic flows to higher-order consumers, including fish species that underpin productive tropical fisheries linked to the livelihoods of millions of people across the tropical world (Robinson et al. 2019, Fulton et al. 2019). As such, we suggest that tropical macroalgal canopy conditions should be a key metric in habitat-based fisheries management and spatial approaches to conservation that seek to encompass a representative cross-section of biodiversity across a range of seascape settings. The thermal thresholds that may underpin major shifts in epifaunal abundance and production should be a key priority for future experimental work and targeted multi-season and multi-year field studies.

Acknowledgements. We thank Maria Eggertsen, David Ellis, Rosalie Harris, Joshua van Lier and Adrienne Nicotra for field assistance and helpful discussions; and 2 anonymous reviewers for helpful comments on an earlier draft. Funding was provided by the Research School of Biology at The Australian National University, the Ministry of Education Taiwan, and a Joyce W. Vickery Scientific Research Award from The Linnean Society of NSW.

\section{LITERATURE CITED}

Anderson MJ, Ellingsen KE, McArdle BH (2006) Multivariate dispersion as a measure of beta diversity. Ecol Lett 9: 683-693

Anderson MJ, Gorley RN, Clarke KR (2008) PERMANOVA+ for PRIMER: guide to software and statistical methods. PRIMER-E, Plymouth

Ateweberhan M, Bruggemann JH, Breeman AM (2009) Seasonal changes in size structure of Sargassum and Turbinaria populations (Phaeophyceae) on tropical reef flats in the Southern Red Sea. J Phycol 45:69-80 
Ba-Akdah MA, Satheesh S, Al-Sofyani AA (2016) Habitat preference and seasonal variability of epifaunal assemblages associated with macroalgal beds on the Central Red Sea coast, Saudi Arabia. J Mar Biol Assoc UK 96: 1457-1467

Belattmania Z, Chaouti A, Reani A, Engelen AH, Machado M, Serrao EA, Sabour B (2018) The introduction of Sargassum muticum modifies epifaunal patterns in a Moroccan seagrass meadow. Mar Ecol 39:e12507

Berkström C, Lindborg R, Thyresson M, Gullström M (2013) Assessing connectivity in a tropical embayment: fish migrations and seascape ecology. Biol Conserv 166: 43-53

Brey T, Muller-Wiegmann C, Zittier ZMC, Hagen W (2010) Body composition in aquatic organisms - a global data bank of relationships between mass, elemental composition and energy content. J Sea Res 64:334-340

Burnham KP, Anderson DR (2002) Model selection and multi-model inference: a practical information-theoretic approach, 2nd edn. Springer, New York, NY

Carvalho NF, Grande H, Rosa JS, Jacobucci GB (2018) The structure of gammarid amphipod (Crustacea, Peracarida) assemblages associated with Sargassum (Phaeophyta, Fucales) and their link with the structural complexity of algae. Hydrobiologia 820:245-254

Edgar GJ (1990a) Population regulation, population-dynamics and competition amongst mobile epifauna associated with seagrass. J Exp Mar Biol Ecol 144:205-234

Edgar GJ (1990b) The influence of plant structure on the species richness, biomass and secondary production of macrofaunal assemblages associated with Western Australian seagrass beds. J Exp Mar Biol Ecol 137:215-240

Edgar GJ (1990c) The use of the size structure of benthic macrofaunal communities to estimate faunal biomass and secondary production. J Exp Mar Biol Ecol 137: 195-214

Edgar GJ, Aoki M (1993) Resource limitation and fish predation: their importance to mobile epifauna associated with Japanese Sargassum. Oecologia 95:122-133

* Edgar GJ, Klumpp DW (2003) Consistencies over regional scales in assemblages of mobile epifauna associated with natural and artificial plants of different shape. Aquat Bot 75:275-291

Engelen AH, Primo AL, Cruz T, Santos R (2013) Faunal differences between the invasive brown macroalga Sargassum muticum and competing native macroalgae. Biol Invasions 15:171-183

Fahrig L (2013) Rethinking patch size and isolation effects: the habitat amount hypothesis. J Biogeogr 40:1649-1663

Froese R, Pauly D (eds) (2019) FishBase. www.fishbase.org (accessed Feb 2019)

Fulton CJ, Depczynski M, Holmes TH, Noble MM, Radford B, Wernberg T, Wilson SK (2014) Sea temperature shapes seasonal fluctuations in seaweed biomass within the Ningaloo coral reef ecosystem. Limnol Oceanogr 59: 156-166

Fulton CJ, Abesamis RA, Berkström C, Depczynski M and others (2019) Form and function of tropical macroalgal reefs in the Anthropocene. Funct Ecol 33:989-999

* Gestoso I, Olabarria C, Troncoso JS (2010) Variability of epifaunal assemblages associated with native and invasive macroalgae. Mar Freshw Res 61:724-731

Gestoso I, Olabarria C, Troncoso JS (2012) Effects of macroalgal identity on epifaunal assemblages: native species versus the invasive species Sargassum muticum. Helgol
Mar Res 66:159-166

*Hensgen GM, Holt GJ, Holt SA, Williams JA, Stunz GW (2014) Landscape pattern influences nekton diversity and abundance in seagrass meadows. Mar Ecol Prog Ser 507:139-152

Huisman JM (2019) Marine plants of Australia. University of Western Australia Press, Crawley

Kobryn HT, Wouters K, Beckley LE, Heege T (2013) Ningaloo Reef: shallow marine habitats mapped using a hyperspectral sensor. PLOS ONE 8:e70105

Kodama M, Kawamura T, Nakamoto K, Ohtsuchi N and others (2020) Effect of algal phenology on seasonal dynamics of gammarid assemblages: differences between canopy and understory strata in a Sargassum yezoense bed. Mar Ecol Prog Ser 634:63-76

K Kramer MJ, Bellwood DR, Bellwood O (2012) Cryptofauna of the epilithic algal matrix on an inshore coral reef, Great Barrier Reef. Coral Reefs 31:1007-1015

Kramer MJ, Bellwood DR, Bellwood O (2014) Benthic Crustacea on coral reefs: a quantitative survey. Mar Ecol Prog Ser 511:105-116

Kramer MJ, Bellwood O, Fulton CJ, Bellwood DR (2015) Refining the invertivore: diversity and specialisation in fish predation on coral reef crustaceans. Mar Biol 162: 1779-1786

Kramer MJ, Bellwood DR, Taylor RB, Bellwood O (2017) Benthic Crustacea from tropical and temperate reef locations: differences in assemblages and their relationship with habitat structure. Coral Reefs 36:971-980

Kulbicki M, Guillemot N, Amand M (2005) A general approach to length-weight relationships for New Caledonian lagoon fishes. Cybium 29:235-252

Kanham BS, Gribben PE, Poore AGB (2015) Beyond the border: effects of an expanding algal habitat on the fauna of neighbouring habitats. Mar Environ Res 106:10-18

Lefevre CD, Bellwood DR (2010) Seasonality and dynamics in coral reef macroalgae: variation in condition and susceptibility to herbivory. Mar Biol 157:955-965

* Leite FPP, Turra A (2003) Temporal variation in Sargassum biomass, Hypnea epiphytism and associated fauna. Braz Arch Biol Technol 46:665-671

Lim IE, Wilson SK, Holmes TH, Noble MM, Fulton CJ (2016) Specialization within a shifting habitat mosaic underpins the seasonal abundance of a tropical fish. Ecosphere 7 : $1-13$

Martin-Smith KM (1993) Abundance of mobile epifauna: the role of habitat complexity and predation by fishes. J Exp Mar Biol Ecol 174:243-260

* Marzinelli EM, Leong MR, Campbell AH, Steinberg PD, Verges A (2016) Does restoration of a habitat-forming seaweed restore associated faunal diversity? Restor Ecol 24:81-90

Mukai H (1971) The phytal animals on the thalli of Sargassum serratifolium in the Sargassum region, with reference to their seasonal fluctuations. Mar Biol 8:170-182

*Noble MM, van Laake G, Berumen ML, Fulton CJ (2013) Community change within a Caribbean coral reef marine protected area following two decades of local management. PLOS ONE 8:e54069

Robinson JPW, Wilson SK, Robinson J, Gerry C and others (2019) Productive instability of coral reef fisheries after climate-driven regime shifts. Nat Ecol Evol 3:183-190

Stella JS, Jones GP, Pratchett MS (2010) Variation in the structure of epifaunal invertebrate assemblages among coral hosts. Coral Reefs 29:957-973 
Tanaka MO, Leite FPP (1998) The effect of sieve mesh size on the abundance and composition of macrophyte-associated macrofaunal assemblages. Hydrobiologia 389:21-28

Tano S, Eggertsen M, Wikstrom SA, Berkström C, Buriyo AS, Hailing C (2016) Tropical seaweed beds are important habitats for mobile invertebrate epifauna. Estuar Coast Shelf Sci 183:1-12

Taylor RB (1998) Density, biomass and productivity of animals in four subtidal rocky reef habitats: the importance of small mobile invertebrates. Mar Ecol Prog Ser 172: $37-51$

van Lier JR, Wilson SK, Depczynski M, Wenger LN, Fulton CJ (2018) Habitat connectivity and complexity underpin fish community structure across a seascape of tropical macroalgae meadows. Landsc Ecol 33:1287-1300

Veiga P, Rubal M, Sousa-Pinto I (2014) Structural complexity of macroalgae influences epifaunal assemblages associ- ated with native and invasive species. Mar Environ Res 101:115-123

*Wainwright PC (1988) Morphology and ecology: functional basis of feeding constraints in Caribbean labrid fishes. Ecology 69:635-645

*Wenger LN, van Lier JR, Fulton CJ (2018) Microhabitat selectivity shapes the seascape ecology of a carnivorous macroalgae-associated tropical fish. Mar Ecol Prog Ser 590:187-200

* Wilson SK, Depczynski M, Fisher R, Holmes TH, O'Leary RA, Tinkler P (2010) Habitat associations of juvenile fish at Ningaloo Reef, Western Australia: the importance of coral and algae. PLOS ONE 5:e15185

*Wilson SK, Fulton CJ, Depczynski M, Holmes TH, Noble MM, Radford B, Tinkler P (2014) Seasonal changes in habitat structure underpin shifts in macroalgae-associated tropical fish communities. Mar Biol 161:2597-2607

\section{Appendix}
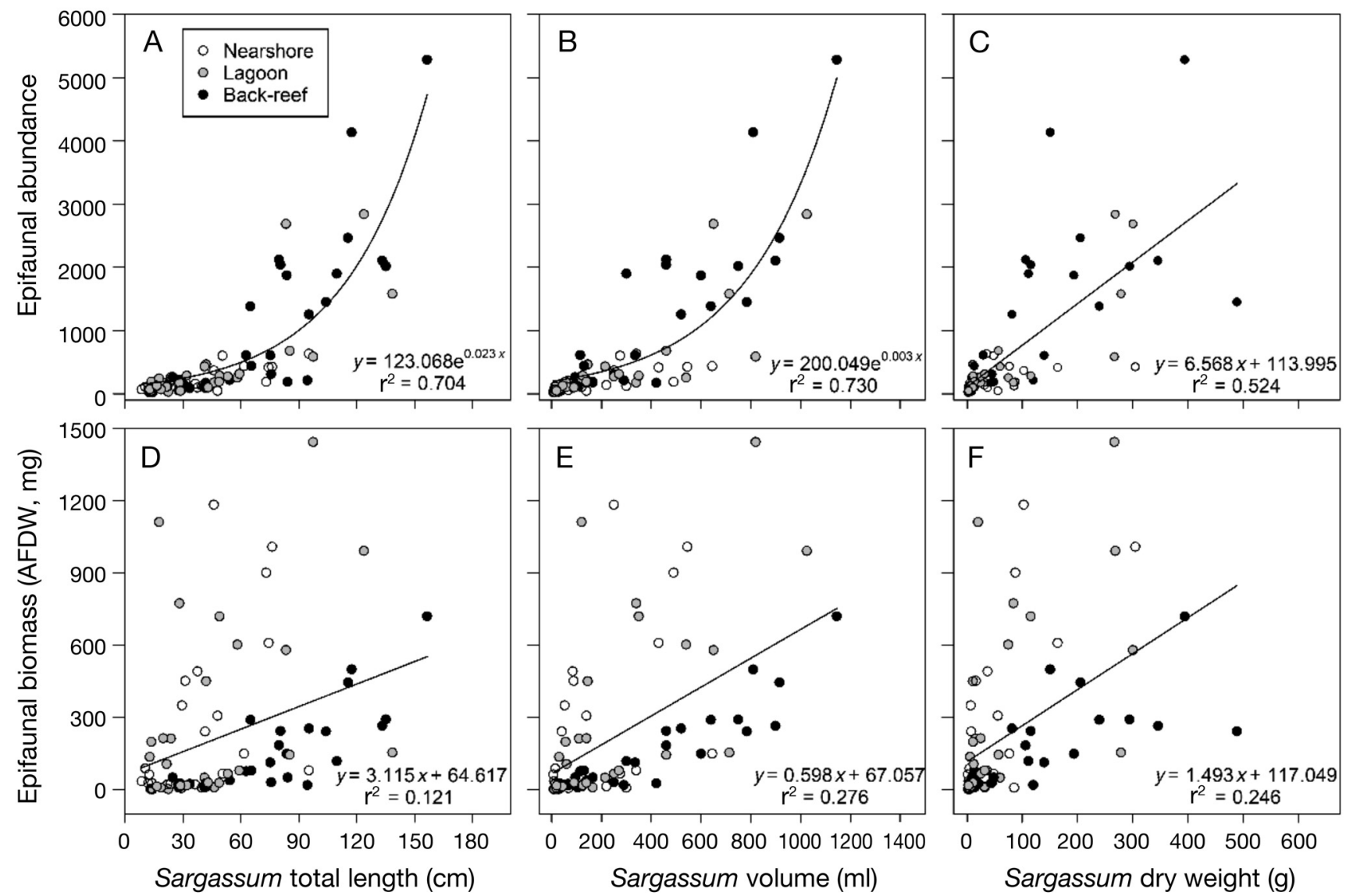

Fig. A1. Relationship between different measures of Sargassum canopy size (total length, volume, and dry weight) and either (A-C) epifaunal abundance (total individuals per S. polycystum) or (D-F) epifaunal biomass (ash-free dry weight per $S$. polycystum) collected from 9 study sites at 3 seascape positions (nearshore, lagoon, and back reef) in the Maud region of Ningaloo Reef, Australia, during summer 2018

Editorial responsibility: Adriana Vergés, Sydney, New South Wales, Australia
Submitted: October 11, 2019; Accepted: March 2, 2020

Proofs received from author(s): April 8, 2020 